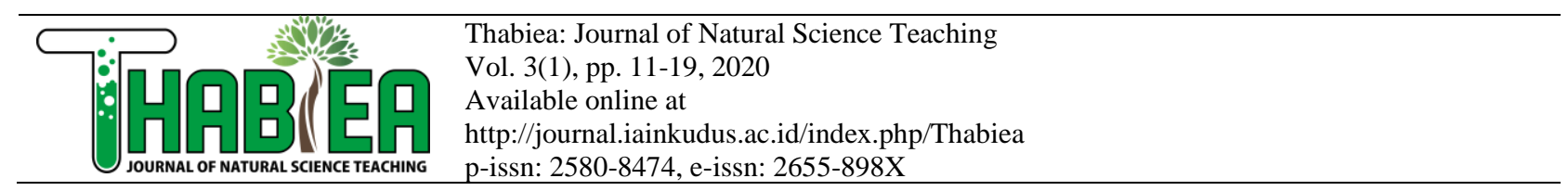

\title{
Implementation of STEM-Robotics as High School Intra-curricular
}

\author{
Abdul Latip ${ }^{1 *}$, Aristo Hardinata ${ }^{2}$ \\ ${ }^{1}$ Science Education Program, Garut University, Samarang Street No. 52 A \\ ${ }^{2}$ Science Education Program, Medan State of University, Willem Iskandar Street, Pasar V \\ *Correspondence: abdullatip@uniga.ac.id
}

\begin{tabular}{ll}
\hline & Abstract \\
\hline Keyword: & The study aim to describe STEM-Robotic implementation as an intra-curricular in \\
STEM & regular curriculum. STEM-Robotics is usually implemented as an extracurricular \\
Robotic & program in many schools. In the 2019/2020 school year, Edu Global Senior High \\
Intra-curricular & School Bandung implemented STEM-Robotics as an intra-curricular for the ten-grade \\
& science program. STEM-Robotic implementation as an intra-curricular based on the \\
& challenges of 21st-century learning that lead to innovative creative learning and skills \\
& development. The method in this study is descriptive qualitative research method \\
& through the observations, questionnaires, and interview with teacher teams. The results \\
& of this study show that, 1) The implementation of STEM-Robotic as an intra-curricular \\
& has a curriculum that focuses about robots NXT and Arduino to provide the basics of \\
& engineering and technological skills in robotics and coding, while the concepts of \\
& science and mathematics have not been directly linked in STEM-Robotic, 2) The \\
& implementation of STEM-Robotic dominated by hands-on and mind-on activities in \\
& the learning process and its assessment. 3) Generally, students responded positively to \\
& the implementation of STEM-Robotics as an intra-curricular that makes learning more \\
& interesting, useful, fun, challenging, and develop engineering and technology skills. \\
& This result indicates that STEM-Robotic is an alternative subject or learning strategy \\
& in regular curriculum to accommodate science learning with educational robotics. \\
\hline
\end{tabular}

To cite this article:

Latip, A.,Hardinata, A. (2020). Implementation of STEM-Robotics as High School Intracurricular. Thabiea: Journal of Natural Science Teaching, 3(1), 11-19.

\section{Introduction}

Industrial revolution 4.0 exerted influence on various fields, including the learning process in classroom. In the era of the rapid development of science and technology, the learning process must be more creative and innovative by paying attention to the needs of the era. Learning in the classroom is expected to equip students with a variety of 21 st-century skills that were oriented to the development of problem-solving, cognitive, creative, critical, collaborative, and communicative skills. These skills are skills demands that must be mastered by students living in the 21 st-century (Greenstein, 2012).

The provision of 21st-century skills aims to prepare students to face the increasingly fierce and tangible globalization competition. Turiman, et al (2012) states that the 21stcentury demands and offers the challenges of life without borders, globalization, and internationalization. Referring to these demands, learning expected to accommodate hands-on and mind-on through various learning activities that are not just transferring knowledge from the teacher to students. More than that, learning is expected to involve technology and digitalization as part of adjusting to the era and collaboration between individuals, groups, 
and machines (McCoog, 2008). In line with that, Jiea, et al (2018) stated that digitalization in education can lead learning to collaboration between individuals and groups.

The development of various skills, technology engagement, and digitalization in learning has been carried out by many stakeholders in education, including teachers. The teachers were package learning through the selection of media, models, approaches, and learning methods. STEM is one approach that accommodates the development of various skills and involved technology in classroom learning. In STEM implementation, learning is packaged by integrated science, technology, engineering, and mathematics. Lantz (2009) states that STEM is a subject related to the development of students' skills to succeed in global work. Moreover, (Permanasari, 2016) states that STEM is an alternative learning approach that can build a generation to face the challenges of the 21 st-century through training students to apply their knowledge to solve environmental problems using technology.

The implementation of STEM in the classroom learning was also integrated with other fields, such as the field of art or STEAM (science, technology, engineering, art, and mathematics). In other implementations, STEM also is integrated with robotics as part of the development of engineering and technological designs. Withehead (2010) states that robotics is a technology that can be used by teachers to develop STEM curricula that more specific to technology and engineering. In line with this, integration of robotic in STEM subject can create an environment learning that encourages hands-on activity, creativity and problem solving (Jiea, et al, 2018), creates more meaningful learning and equips technology application experience to students (Carik and Guven, 2019), and improving basic STEM skills such as mathematical skills, scientific methods, and skills in engineering design (Eguchi, 2013; Karaahmetoglu and Korkmaz, 2019).

Integration of robotic in STEM can also increase students' interest in STEM, both in STEM learning and in future career selection related to STEM (Ebelt, 2012; Khanlari, 2013; Mosley, Ardito, and Scollins, 2016; Chen and Chang, 2018). However, although these robotics are popular in the field of education, the facts in the field show that robotics is still used as an extracurricular program (Gura, 2011; Eguchi, 2013). In the 2019/2020 school year, Edu Global Senior High School made STEM-Robotics as an intra-curricular for ten-grade students of Sciences program. The implementation of robotics in STEM learning aims to develop students' various skills and answer the challenges of the rapid development of science and technology. Based on the description, this article will be discussed and described regarding the results of study on the implementation of STEM Robotics as an intra-curricular in Edu Global Senior High School Bandung.This study focused on the discussion of the development of STEM-Robotic curriculum, the implementation of STEM-Robotic learning as an intra-curricular/regular curriculum, and the students' responses of participating in STEMRobotic learning.

\section{Method}

The research method of this study is a descriptive qualitative method. Qualitative research methods lead to a variety of interpretation techniques and assessment of participant perspectives with multiple strategies, namely interactive strategies such as direct observation, questionnaires, and reviewing documents (Merriam, 2009). In this research, researchers conducted observations on STEM-Robotic learning in ten-grade students of Edu Global 
Senior High Bandung during 10 meetings of learning. The researchers observed the implementation of curriculum Lego NXT in STEM-Robotic learning for the first up to fourth meetings of learning. In the fifth up to end meetings of learning, the researchers observed the implementation of curriculum Arduino device to support STEM-Robotic learning. Besides, the researchers also reviewed the documents of the STEM-Robotic curriculum. This document developed by the STEM-Robotic teacher team. The researcher also gave the questionnaires to students in STEM-Robotic learning.

The data obtained from each stage of the research process were analyzed, processed, and described as research findings and results. The direct observation in classroom learning using the instrument of observation and obtained the descriptive data of implementation STEM with robotic as a tool to support the learning process. The reviewed document curriculum STEM-Robotic obtain the descriptive data of curriculum Lego NXT and Arduino device in STEM learning. The student responses about STEM-Robotics collected by questionnaire with a Likert scale. The result of the questionnaires displayed in percentage of students' responses about implementation of STEM-Robotics.

\section{Results and Discussion}

The results and discussion in this article based on an analysis of research findings of the implementation of STEM-Robotic as an intra-curricular in Edu Global Senior High School Bandung. Results and discussion focused on 3 main studies, namely 1). Development of STEM-Robotic curriculum, 2). Implementation of STEM-Robotic as an intra-curricular, and 3). The students' responses to STEM-Robotic learning. The results and discussion of the three main studies are as follows:

\section{Development of STEM-Robotic Curriculum as intra-curricular}

The development of STEM-Robotic curriculum conducted by STEM-Robotic teacher team, the development taking into the minimum achievement of skills that must be mastered by students, the minimum achievement of skills must strengthen STEM concepts, namely science, technology, engineering, and mathematics. Besides, the development of the STEMRobotic curriculum must also pay attention to supporting learning facilities in schools, such as the availability of tools and robotics equipment.

Development of STEM-Robotic curriculum does not refer to the national curriculum, because the national curriculum has not STEM-Robotic as a subject in the regular curriculum. The development of STEM-Robotic curriculum based on various skills that will support when learning STEM concepts. Jiea, et al, (2018) stated development of Robotic curriculum in STEM dose not to replace the existence of science and mathematics curriculum, but it is an alternative way and media that can be used by teachers to prepare students to be literate of STEM and get to know the world of work in the STEM field.The description of STEMRobotic curriculum about main subject and sub-topics is as follows: 
Table 1. The Main and Sub-Subjects of STEM-Robotic

\begin{tabular}{ccll}
\hline No & Main Subject & \multicolumn{1}{c}{ Main Sub } \\
\hline 1 & NXT robot lego & $\begin{array}{l}\text { The basic form of NXT, NXT program, Sensors on NXT robots } \\
\text { (sound, ultrasonic, touch, and light), and Steering Wheel }\end{array}$ \\
\hline 2 & Arduino & $\begin{array}{l}\text { Arduino basic theory (understanding, types, basic syntax), } \\
\text { Microcontroller, Led and Button, and Sevensegment }\end{array}$ & \\
\hline
\end{tabular}

Table 1 shows the main and sub-topics in the STEM-Robotic curriculum for one semester. The main STEM-Robotic curriculum for the first semester focused on material about Lego NXT and Arduino. Lego NXT is an educational robotics device that can be programmed as desired. Programming can be run in lego NXT include NXT-G and Next Byte Codes. The selection of lego NXT and Arduino based on many results of research, it showed that lego NXT and Arduino are educational robotic devices can develop many skills, such as science process skills, problem-solving skills, and cooperative skills (Eguchi, 2013). Besides, lego NXT and Arduino can also provide more opportunities for effective learning when learning physics, biology, mathematics, geography, science, electronics, and mechanical engineerin (Eguchi, 2013).

Irigoyen, et al (2013) stated Lego NXT and Arduino have various elements that connected with various devices and linked with variables studied in science, such as pressure, light, sound, and temperature. More specifically, Carik and Guven (2019) state that Arduino and coding can help students to visualize abstract scientific concepts and make learning science more enjoyable. According to that, lego NXT and Arduino will help students to develop and strengthening knowledge and skills in the STEM field.The selection of lego NXT and Arduino also based on the ease of getting this platform and having an affordable price for the School. Irigoyen, et al (2013) states that Lego NXT and Arduino are educational robotic platforms that have low prices. Moreover, Lego NXT and Arduino are also basic of robotics platforms that can be developed by educated participants on other educational robotic platforms.

Developing of STEM-Robotic curriculum can also review from the expected achievements by students after studied the STEM-Robotic. The basic competence that must be mastered by students after studied STEM-Robotic during the odd semester on lego NXT material were: 1) assemble the basic form NXT robotic, 2) programming the NXT to move the wheels, 3) moving the robot using sound sensors, ultrasonic, touch and light, and 4) assemble the Lego NXT in the form of a steering wheel and run it along the line until the finish. The basic competence of students' skill for Arduino material are: 1) understanding the basic theory of Arduino (microcontroller, type, and syntax), 2) understanding the concepts of LEDs and resistors (making circuits and counting resistors), 3) practicing how to turn on LEDs, 4) understanding the LED concept and button (understanding polarity and making a circuit), 5) practicing how to light an LED through a button, 6) understanding the concept of seven-segment (understanding polarity, and circuit), and 7) practicing how to turn on sevensegment until it forms zero to nine number (0-9).

Based on the elaboration of basic competence in lego NXT and Arduino, it can summarize that the STEM-Robotic curriculum for the first semester has more focus on handson and mind-on activities during the learning process. Besides, the STEM-Robotic curriculum 
in the first semester also dominated by concepts that lead to strengthening engineering and technology skills, while the concepts of science and mathematics still get a smaller portion.

\section{Implementation of STEM-Robotic Learning as Intra-curricular}

The implementation of STEM-Robotics learning as an intra-curricular is a description of the implementation of STEM-Robotics learning during 10 learning meetings. Description of STEM-Robotic implementation explains the learning process and assessment in STEMRobotic learning. Explanation of the implementation of STEM-Robotics based on the result of the analysis of observations in class. STEM-Robotic or educational robotic learning is one of the tools in an extracurricular activities program. Although educational robotics is very popular in the education field, robotics does not yet include in the regular curriculum schedule (Gura, 2011; Eguchi, 2013). In the 2019/2020 school year, Edu Global Senior High School Bandung made the integration of STEM-Robotic as an intra-curricular for the ten-grade science program.

Implementation of STEM-Robotic subjects gots 2 hours of learning ( 2 x 45 minutes) in one week. In the odd semester of the 2019/2020 school year, STEM-Robotic learning consists of twelve for learning meetings, one meeting for midterm assessment, one meeting for final semester assessment, and four meetings for the daily skills exam. Every STEMRobotic lesson, students make grouped with members of each group consisting of 4-5 people. Each group was given one lego NXT and Arduino. Every group also required to bring a laptop to make a simple program of coding that supports lego NXT and Arduino. The program of coding used to run the lego NXT and Arduino robots that studied at the lesson.

The teacher team of STEM-Robotics has the role of main and accompanying teacher. The main teacher delivered the main subject material to all students. The accompanying teacher assisted each group during the learning activities, especially in completing project STEM-Robotic learning. The implementation of STEM-Robotic learning does not just a transfer of information from the teacher to students. More than that, the hands-on activities of students are very dominating during the learning process. The result same with the opinions and research findings (McKay, 2015; Hinton, 2017; Jiea, et al. 2018; Blackley and Howell, 2019) states that integration of STEM learning with robotics can increase the hands-on activities of students.

The hands-on activity in STEM-Robotic learning can show from the activities of students in designing a basic form of lego NXT robotics, steering wheels, and designing Arduino devices with all components. STEM-Robotic learning accompanied by minds-on activities in the making programs and coding to run lego NXT and Arduino robots. According to these activities, students in his group must take a strategy to complete each learning material and project during STEM-Robotic learning. The setting of STEM-Robotic learning leads to the development of various skills, including collaborative skill, problem-solving, critical, and creative skills. This statement same with several studies which state that integrated STEM with robotics can improve students' collaborative skills (Eguchi, 2013; Mosley, 2016; Hinton, 2017; Jiea, et al, 2018; Cakir and Guven, 2019; Anwar, et al, 2019; Chen and Chang, 2019), improve problem-solving skills (McKay, 2015; Menekse, 2017; Jiea, et al, 2018; Chen and Chang, 2019) and improve critical and creative thinking skills (Menekse, et al, 2017; Chen and Chang, 2019).

Besides the learning process, the assessment of STEM-Robotics also focuses on many 
skills. The assessment consists of daily skills tests, midterm tests, and final semester tests. All assessments lead to skills tests that involve hands-on and mind-on activities in designing and programming a STEM-Robotic project. The results of the assessment presented in a special report card STEM-Robotic which contains the scores obtained for each project, the average score of project, predicate, and description of the skills that have been achieved by students. Based on the analysis of STEM-Robotic students' report cards during one semester, the final score of the student in STEM-Robotic subjects as follows:

Table 2. Students' Final Score in STEM-Robotic Subjects

\begin{tabular}{ccc}
\hline Value Range & Predicate & \% Total students \\
\hline $100-91$ & A (Very good) & $33.33 \%$ \\
$90-89$ & B (Good) & $55.55 \%$ \\
$80-71$ & C (enough) & $11.11 \%$ \\
\hline
\end{tabular}

Table 2 shows that most students have been able to complete each STEM-Robotics project well, starting from the assembly process, design to making the program/coding to run the lego NXT and Arduino robots. Even so, there are still students who have difficulties in the main subject of STEM-Robotic, such as assembly Arduino devices and making programs/coding to run the lego NXT or Arduino robots.

\section{Students' Responses to STEM-Robotic Learning}

In this study, data of students' responses collected through questionnaires at the end of STEM-Robotic learning in the odd semester of the 2019/2020 school year. The questionnaire consists of two main contents, namely the existence of STEM-Robotics as a subject in regular curriculum and the relationship of STEM-Robotic learning with fields in STEM. The questionnaire prepared using a Likert scale with a choice of responses, namely strongly agree (SA), agree (A), doubtful/neutral $(\mathrm{N})$, disagree (D), and strongly disagree (SD). The results of this questionnaire were processed and presented as a percentage. Table 3 showed students' responses to the existence of STEM-Robotic subjects as a regular curriculum.

Table 3. Students' responses to STEM-Robotic Learning

\begin{tabular}{cccccc}
\hline \multirow{2}{*}{ Response Item } & \multicolumn{5}{c}{ Response Type (\%) } \\
\cline { 2 - 6 } & SD & D & N & A & SA \\
\hline STEM-Robotic Useful & 0.00 & 0.00 & 5.56 & 61.11 & 33.33 \\
STEM-Robotic Attractive & 0.00 & 0.00 & 0.00 & 44.44 & 55.56 \\
STEM-Robotic Challenging & 0.00 & 0.00 & 0.00 & 16.67 & 83.33 \\
STEM-Robotic Fun & 0.00 & 0.00 & 0.00 & 61.11 & 38.89 \\
\hline
\end{tabular}

Generally, students gave positive responses about the existence of STEM-Robotics as an intra-curricular. The students' responses showed that STEM-Robotics is a useful, interesting, challenging, and fun. The result was the same with several research findings that state educational robotics can increase students' interest in STEM learning, make learning more interesting and enjoyable (Ebelt, 2012; Mosley, et al, 2016; Chen and Chang, 2018; Carik and Guven, 2019). The questionnaire also collected students' responses about the 
relationship of STEM-Robotics with science, technology, machinery, and mathematics. The results of the questionnaire are as follows:

Table 4. Students' Responses about Relationship STEM-Robotic with Fields of STEM

\begin{tabular}{lccccc}
\hline \multirow{2}{*}{ Response Item } & \multicolumn{5}{c}{ Response Type (\%) } \\
\cline { 2 - 6 } & SD & D & N & A & SA \\
\hline $\begin{array}{l}\text { STEM-Robotic make science easy to } \\
\text { understand }\end{array}$ & 0.00 & 0.00 & 55.56 & 38.89 & 5.56 \\
\hline STEM-Robotics improve engineering skills & 0.00 & 0.00 & 0.00 & 66.67 & 33.33 \\
\hline $\begin{array}{l}\text { STEM-Robotic makes mathematics easy to } \\
\text { understand }\end{array}$ & 0.00 & 0.00 & 72.22 & 27.78 & 0.00 \\
\hline STEM-Robotic makes literate of technology & 0.00 & 0.00 & 0.00 & 83.33 & 16.67 \\
\hline
\end{tabular}

Table 4 showed that students gave positive responses about relationship STEMRobotic with engineering skills and technology literacy. Engineering and technology are the main fields that dominate STEM-Robotic learning, especially in the process of designing, assembling, and making a coding. Other responses, students gave a neutral response to the relation of the STEM-Robotics with science and mathematics. The lesson of STEM-Robotics has not received more tangible benefits to be applied in the fields of science and mathematics. The majority of neutral responses based on the packaging of STEM Robotic content that has not been directly linked with science and mathematics. Besides that, the portion of content science and mathematics in STEM-Robotic learning has not been given as much as the portion of engineering and technology content.

\section{Conclusion}

STEM as a part of the learning approach has been conducted by many teachers in the learning process. In its development, STEM has also been integrated with many other fields. In this research, STEM was integrated with robotics as an effort to develop 21st-century skills, especially technology and engineering skills. In its implementation, STEM-Robotic is usually an extracurricular activity that is not included in the regular curriculum. In the 2019/2020 school year, Edu Global Senior High School Bandung made STEM-Robotic as a subject (intra-curricular) in regular curriculum. The results of study about STEM-Robotic Implementation as an intra-curricular show that: 1) STEM-Robotic as an intra-curricular has a curriculum that focuses on material about lego NXT and Arduino robots. The curriculum aimed to provide students with the basics of engineering and technology skills in the field of robotics and coding. The STEM-Robotic curriculum has not been directly linked with science and mathematics concepts. 2) The implementation of STEM-Robotic as an intra-curricular dominated by hands-on and minds-on activities in the learning process and its assessment. 3) Generally, students gave a positive response to the implementation of STEM-Robotic as an intra-curricular. STEM-Robotic makes learning more interesting, useful, fun, and challenging. Besides, the students also responded that STEM-Robotic provides opportunities to improve engineering and technology skills. 


\section{References}

Anwar, S. et al. (2019). A Systematic Review of Studies on Educational Robotics. Journal of Pre-College Engineering Education Research. 9 (2). 19-42.

Blackley and Howell. (2019). The Next Chapter in the STEM Education Narrative: Using Robotics to Support Programming and Coding. Australian Journal of Teacher Education. 44(4), 51-64.

Cakir and Guven. (2019). Arduino-Assisted robotic and coding applications in science teaching: Pulsimeter activity in compliance with the 5E learning model. Science Activities.https://doi.org/10.1080/00368121.2019.1675574.

Chen and Chang. (2018). The Impact of an Integrated Robotics STEM Course with a Sailboat Topic on High School Students' Perceptions of Integrative STEM, Interest, and Career Orientation. EURASIA Journal of Mathematics, Science and Technology Education. 14(12), 1-19.

Ebelit, R. (2012). "The Effects of a Robotics Program on Students Skills in STEM, Problem Solving and Teamwork. Science Education. Montana State University. Bozeman, Montana.

Eguchi. A. (2013). Educational Robotics for Promoting 21st Century Skills. Journal of Automation, Mobile Robotics \& Intelligent Systems. 8(1), 5-11.

Goh and Bilal Ali. (2014). Robotics as a Tool to STEM Learning. International Journal for Innovation Education and Research. 2(10), 66-78.

Gura, M. (2011). Getting Started with LEGO Robotics: A Guide for K-12 Educators. Retrieved 22 Dec. 2019, from http://www.iste.org/images/excerpts/ROBOTSexcerpt.pdf.

Greenstein, L. (2012). Assessing 21st Century Skills: A Guide to EvaluatingMastery and Authentic Learning. California: Corwin A Sage Company.

Hinton, T.R. (2017). "An Exploratory Study of a Robotics Educational Platform on STEM Career Interests in Middle School Students". Department of Educational Leadership, Policy, and Technology Studies in the Graduate School of The University of Alabama. Tuscaloosa.

Irigoyen, et al. (2013). Low-cost platforms used in Control Education: An educational case study. 10th IFAC Symposium Advances in Control Education The International Federation of Automatic Control, August 28-30, 2013. Sheffield, UK.

Jiea, et al. (2018). Integrated Robotics STEM Curriculum Towards Industry 4.0. International Journal of Human and Technology Interaction. 2(2), 17-23.

Karaahmetoglu and Korkmaz. (2019). The effect of project-based arduino educational robot applications on students' computational thinking skills and their perception of Basic STEM skill levels. Participatory Educational Research (PER). 6(2), pp.1-14.

Khanlari. (2013). Effects of Educational Robots on Learning STEM and on Students' Attitude Toward STEM. 2013 IEEE 5th Conference on Engineering Education (ICEED).

Lantz Jr., H.B. (2009). Science, Technology, Engineering, and Mathematics (STEM) Education What Form? What Function? Retrieved 20 December 2019, from http://www.currtechintegrations.com/pdf/STEMEducationArticle.pdf.

McCoog, I.J. (2008). 21st Century Teaching an Learning. Education Resource Center. Retrieved 19 December 2019, from http://www.eric.ed.gov/PDFS/ED502607.pdf. 
McKay, M. (2015). Student Learning of STEM Concepts Using a Challenge-based Robotics Curriculum. In Proceedings of 2015 ASEE Annual Conference \& Exposition, Seattle, Washington. https://doi.org/10.18260/p.24756.

Menekse, et al. (2017). The Role of Robotics Teams' Collaboration Quality on Team Performance in a Robotics Turnament. Journal of Enggineering Education. 106 (4), 564-584. https://doi.org/10.1002/jee.20178.

Merriam, S.B. (2009). Qualitative Research in Education: A Guide to Design and Implementation. San Fransisco: John Wiley and Sons, Inc.

Mosley, et al. (2016). Robotic Cooperative Learning Promotes Student STEM Interest. American Journal of Engineering Education. 7 (2), 117-128.

Permanasari, A. (2016). STEM Education : Inovasi dalam Pembelajaran Sains. Prosiding Seminar Nasional Pendidikan Sains (SNPS). 23-34.

Turiman, et al. (2012). Fostering the $2^{\text {st }}$ Century Skills through Scientific Literacy and Science Process Skills. Procedia-Social and Behavioral Sciences. 59:110-116.

Whitehead, S.H., (2010). Relationship of Robotic Implementation on Changes in Middle School Students' Beliefs and Interest Toward Science, Technology, Engineering, and Mathematics. Doctor of Education Dissertation. Indiana University of Pennsylvania. 